\title{
Diagnosing adaptive comanagement across multiple cases
}

\author{
$\underline{\text { Ryan Plummer }}^{1,2}, \underline{\text { Julia Baird }}^{1,3}$, Derek Armitage ${ }^{4}$, Örjan Bodin $^{2}$ and Lisen Schultz $^{2}$
}

\begin{abstract}
Adaptive comanagement is at an important cross-road: different research paths forward are possible, and a diagnostic approach has been identified as a promising one. Accordingly, we operationalize a diagnostic approach, using a framework, to set a new direction for adaptive comanagement research. We set out three main first-tier variables: antecedents, process, and outcomes, and these main variables are situated within a fourth: the setting. Within each of these variables, significant depth of study may be achieved by investigating second- and third-tier variables. Causal relationships among variables, and particularly related to the outcomes of adaptive comanagement, may also be investigated at varying depths using the diagnostic framework and associated nomenclature. We believe that the diagnostic approach we describe offers a unifying methodological approach to advancing adaptive comanagement research as well as similar approaches. There are significant benefits to be gained, including building a database of case studies using this common framework, advancing theory, and ultimately, improving social and ecological outcomes.
\end{abstract}

Key Words: adaptive comanagement; biosphere reserves; diagnostic framework; methods and measurements

\section{INTRODUCTION}

After nearly two decades of diverse adaptive comanagement (ACM) studies, this field of research is at an important juncture, where taking the next step in understanding requires coordinated efforts. While different paths forward are possible, a diagnostic approach has been identified as a particularly promising avenue to allow for this coordination (Plummer et al. 2012, 2014). A diagnostic approach provides a way to build a systematic understanding in complex situations (Meinzen-Dick 2007, Ostrom 2007, 2009, McGinnis and Ostrom 2014). It provides a common set of "tools" to construct causal explanations (McGinnis and Ostrom 2014). We make operational the idea of a diagnostic approach as a new direction for ACM research. Specifically, our aim is to present the core features and dimensions of a diagnostic framework so that future ACM research can be approached in a systematic and comparative manner. This is necessary to build the theory of adaptive comanagement in ways that enhance practice.

Our insights come from a multiyear research project that sought to develop such a framework and to trial the framework in four UNESCO biosphere reserves: two in Canada and two in Sweden. After briefly explaining the rationale for a diagnostic approach, a framework is set out which organizes knowledge about ACM into main variables and presents foundational nomenclature. We subsequently outline a suite of tested methods and established measures for adaptive comanagement, and offer a way to make the diagnostic approach operational for data collection in empirical settings.

How did ACM arrive at a cross-road? Adaptive comanagement emerged as one promising approach to the governance of socialecological systems (Olsson et al. 2004, Folke et al. 2005, Armitage et al. 2007). It combines and builds upon adaptive ecosystembased management and collaborative (co-) management. Adaptive comanagement is understood as "...flexible, community-based systems of resource management tailored to specific places and situations, and supported by and working with various organizations at different scales" (Olsson et al. 2004:75). In theory, it enables faster and more appropriate responses to system change, as it draws on the capacities and competencies of a diverse set of actors, while continuously improving practices in a learning-by-doing process. In addition to offering a suite of ideas or prescriptions about how desirable environmental governance may be accomplished (Huitema et al. 2009), ACM is a real-world phenomenon. In the almost 20 years since its genesis, numerous initiatives have emerged that resemble ACM, in part or fully. Particularly striking is the diversity of situations (e.g., forestry, fisheries, wildlife, waterscapes, parks and protected areas, climate change, settlement) and geographical distribution in which ACM has been documented.

Scholarship on ACM has grown rapidly and generated a host of valuable insights. However, a systematic review (see Plummer et al. 2012) to comprehensively synthesize these insights uncovered a challenging, but not uncharacteristic, issue for a young and developing field. That is, conceptual imprecision and methodological inconsistency has limited the ability to make rigorous comparisons across settings and has precluded drawing robust evidence-based findings about the interrelationships between/among ACM variables, actual outcomes, and successes/ failures. Several important questions therefore remain open. What works where and under what conditions? Which variables are essential to ACM and what is their relationship to outcomes and success (Huitema et al. 2009, Plummer 2009, Plummer et al. 2012, Fabricius and Currie 2015)? Are the promises of improved outcomes (social and ecological) under ACM being realized? Answering such questions requires a common conceptual framework and employment of rigorous methods across cases/ studies to draw stronger causal inferences, limit errors in generalization, and eventually start developing theory (Plummer et al. 2012).

\footnotetext{
${ }^{1}$ Environmental Sustainability Research Centre, Brock University, ${ }^{2}$ Stockholm Resilience Centre, Stockholm University, Sweden, ${ }^{3}$ Department of Geography and Tourism Studies, Brock University, ${ }^{4}$ Environmental Change and Governance Group, School of Environment, Resources and Sustainability, University of Waterloo
} 
Table 1. Nomenclature of variables.

\begin{tabular}{|c|c|c|}
\hline \multicolumn{3}{|c|}{ Variables } \\
\hline First-tier & Second-tier & Third-tier \\
\hline \multirow[t]{3}{*}{ Setting } & Institutional context & $\mathrm{n} / \mathrm{a}$ \\
\hline & $\begin{array}{l}\text { Biophysical conditions (including ecosystem } \\
\text { attributes) }\end{array}$ & $\mathrm{n} / \mathrm{a}$ \\
\hline & Social-ecological linkages & $\mathrm{n} / \mathrm{a}$ \\
\hline \multirow[t]{6}{*}{ Antecedents } & Actors & Type diversity \\
\hline & & Level diversity \\
\hline & Activities and practices & Implementation \\
\hline & & Decision-making \\
\hline & & Monitoring \\
\hline & & Spaces for interaction \\
\hline \multirow[t]{17}{*}{ Process } & Learning & Individual as unit of analysis: \\
\hline & & Cognitive \\
\hline & & Normative \\
\hline & & Relational learning \\
\hline & & Social group or organization as unit of analysis: \\
\hline & & Single loop \\
\hline & & Double loop \\
\hline & & Triple loop learning \\
\hline & Collaboration & Collaborative qualities: \\
\hline & & Legitimacy \\
\hline & & Open communication, negotiation, and mutual respect \\
\hline & & Transactive decision-making \\
\hline & & Pluralism and linkages \\
\hline & & Network structures: \\
\hline & & Social cohesion \\
\hline & & Heterogeneity \\
\hline & & Centralization \\
\hline \multirow[t]{5}{*}{ Outcomes } & Results & First order tangible \\
\hline & & First order intangible \\
\hline & & Second order \\
\hline & Effects & Ecological sustainability \\
\hline & & Human livelihoods \\
\hline
\end{tabular}

\section{A DIAGNOSTIC FRAMEWORK FOR ADAPTIVE COMANAGEMENT}

The complexity of social-ecological systems limits the utility of blueprint approaches and management panaceas (Holling and Meffe 1996, Cox 2011). In contrast, the use of diagnostic approaches has emerged as a strategy to consider complexity in a more systematic manner (Meinzen-Dick 2007, Ostrom 2007, 2009). In the context of social-ecological systems, diagnosis is analogous to health professionals querying symptoms and thereby gaining an understanding of a complex situation: "a [diagnostic] framework provides the basic vocabulary of concepts and terms that may be used to construct the kinds of causal explanations expected of a theory. Frameworks organize diagnostic, descriptive, and prescriptive inquiry" (McGinnis and Ostrom 2014: Why a framework? section, para. 1).

Connections between the notion of a diagnostic approach as advanced by Elinor Ostrom (2007) and its potential to inform understanding of ACM processes have been identified (e.g., Plummer et al. 2012, Whaley and Weatherhead 2014, Fabricius and Currie 2015). In particular, a diagnostic approach was advocated as a way forward for synthesizing research on ACM in specific and coordinated ways that ultimately provide a basis to develop theory (Plummer et al. 2012). Plummer et al. (2014) provided an initial step down this path by proposing a diagnostic framework, conceptually establishing main variables for consideration from antecedent scholarship, and discussing how it may be used in the context of biosphere reserves. In the spirit of continual refinement, we build upon that discussion paper in this section by offering a working framework (Fig. 1) to serve as an organizational device, and present a corresponding common nomenclature for ACM. The spirit of the diagnostic approach and social-ecological systems framework by Ostrom $(2007,2009)$ informs our thinking in important ways (e.g., decomposability of systems, development of nested conceptual maps), but our focus is exclusively on understanding ACM, and we thus emphasize specific antecedents, process hallmarks (i.e., collaboration and learning), and outcomes.

In the following sections, we move from the broadest conceptual level to unpack the variables in nested tiers. Each first- and secondtier variable is briefly described, and then third-tier variables are detailed (see Table 1). The organization of the nested conceptual map for ACM draws upon the utility and logic set forth by Ostrom (2007, 2009), where the higher level variables offer an organizing framework from which more indepth investigations may occur, as well as offering a mechanism for testing relationships between and among variables at a broader level. In our specific framework, the higher level variables offer a common nomenclature to facilitate the systematic accumulation of knowledge about ACM, 
the lower level variables may be operationally tailored to specific ACM inquiries, and in concert, causal inferences may be developed to start building general theory about ACM.

Fig. 1. Framework for diagnosing adaptive comanagement.

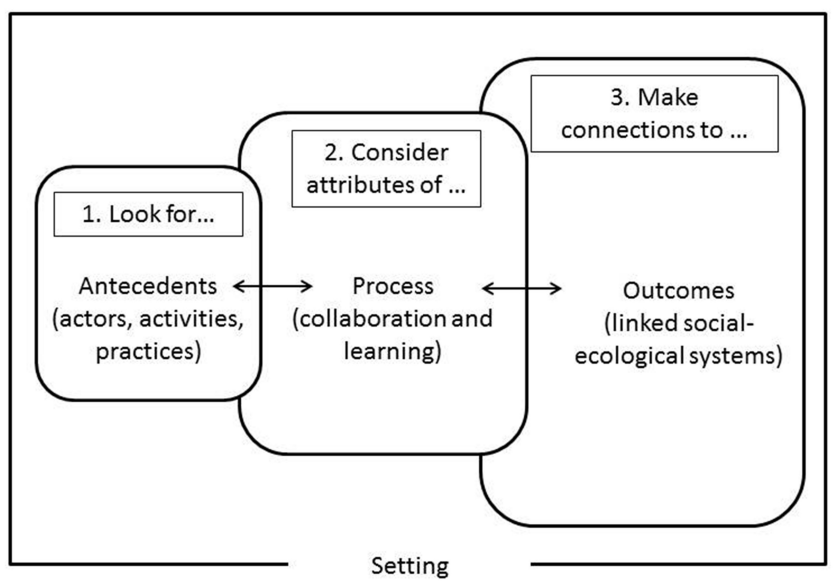

For simplicity, we consistently refer to the study object as the ACM process. However, we wish to clarify that the diagnostic approach is not limited to studying the characteristics of a process being predefined/determined to resemble ACM. Rather, a main merit (as we argue here) is its ability to facilitate cross-case empirical inquiries in relation to if, how, and to what extent the different key features (i.e., variables) of ACM relate to each other and to social and ecological outcomes. Thus, our diagnostic approach will hopefully be of value to scholars who do not necessarily define themselves as specifically interested in ACM but in other similar frameworks (e.g., adaptive governance, biosphere stewardship).

\section{Setting}

Steps for diagnosis are keyed to main variables for analysis, and occur with acknowledgment of the setting in which they are embedded. Adaptive comanagement is tailored to particular places and situations (Olsson et al. 2004, Armitage et al. 2009) and is always related to the setting in which it occurs. The setting informs diagnosis of the condition in a specific circumstance and provides a basis upon which cross-site comparisons are predicated. Attention to the institutional context, biophysical conditions, and social-ecological connections is required.

\section{Antecedents}

Diagnosis begins with the search for antecedents that signal an ACM process-actors, activities, and practices. Antecedents direct attention to circumstances that signal ACM may be present. Interactions among multiple types of actors across decisionmaking levels with some degree of power sharing are essential properties of ACM (Folke et al. 2005, Berkes et al. 2007, Schultz et al. 2011). Activities include what is being done on-the-ground as individuals work together to manage, govern, and/or solve environment and resource challenges in a particular place. Practices draw attention to the manner in which the activities come about and/or the customary performance of the formal or nonformal organization.

\section{Process}

Antecedents are emblematic of an iterative and ongoing process. As actors engage in ACM, a unique process is engendered that brings together and builds upon the linking function of collaboration with the learning aspect of adaptive management (Berkes et al. 2007, Armitage et al. 2009, Plummer et al. 2014). Considering process attributes is the second step in the approach to diagnosing ACM, specifically features of collaboration and learning (Fig. 1).

Collaboration is a major narrative in resource management and environmental governance, with a litany of cases providing valuable insights about opportunities arising when multiple actors come together to pursue a shared interest. In relation to the ACM process, we draw attention to the qualities as well as the structure of collaboration. The quality of the process by which a decision is reached has repeatedly been found to mediate claims about participation in empirical studies of resource and environmental management (Reed 2008). Several works have synthesized principles and attributes that constitute a quality process in this context (e.g., Webler et al. 2001, Lockwood et al. 2010), with more recent works (Sandström et al. 2014, Birnbaum et al. 2015) emphasizing qualities associated with legitimacy (e.g., openness, deliberation, mutual respect, transparency). Many of these qualities transcend collaboration of different types, but specificity is required if empirical appraisals are to be meaningfully considered in relation to the aims and outcomes of the process (Conley and Moote 2003). In this regard, our diagnostic approach is informed by characteristics of ACM and process parameters (Plummer and Armitage 2007), including attributes of pluralism and linkages, communication and negotiation, and transactive decision-making. The structure of collaboration may be understood using a social network approach, where actors engaged in ACM are connected to each other via collaborative ties. The potential of network measures to provide insights into ACM has been highlighted (Folke et al. 2005, Plummer et al. 2012), including network change over time (Baird et al. 2016). Network attributes associated with the ACM process include social cohesion, heterogeneity of actors, and centralization.

Learning, similarly, is an essential ingredient when collectively navigating complexity and uncertainty. We follow Argyris and Schön (1974), and define learning as a social process of iterative reflection that takes place when experiences, ideas, and environments are shared. Individuals as opposed to organizations learn (Fazey et al. 2005), and yet the social situation in which learning occurs is essential. The social unit is thus important to recognize, and we adopt the perspective that learning here is a "...change in understanding that goes beyond the individual to become situated within wider social units or communities of practice through social interactions between actors within social networks" (Reed et al. 2010: Conclusions section, para. 1, Diduck 2010). Effects on cognitive, normative, and relational learning are considered. Attributes of learning at the group or organization social unit of analysis also warrant consideration and draw attention to where errors are corrected from routines (single loop), values and policy adjustments occur (double loop), and governance norms and protocols are revised (triple loop).

\section{Outcomes}

Outcomes are anticipated to arise from the ACM process, and making connections to them is an important aspect of the 
diagnostic framework (Fig. 1). Providing solid evidence that connects decisions to impacts on ecosystems and human wellbeing is essential to accelerate momentum toward sustainable development (Guerry et al. 2015). The third step in our approach builds upon the resilience-based proposal for evaluating ACM by Plummer and Armitage (2007), and has been discussed in relation to diagnosis and cross-site comparisons (Plummer et al. 2014). Outcomes coming about from ACM are accordingly considered as to results and effects. Results are products (tangible and intangible) arising from the ACM process. They may stem from the initiative immediately (first order) or indirectly (second order) (cf Innes and Booher 1999). Whereas results capture what comes about from ACM, effects entail their consequences. Contributions from ACM in this regard are appraised with consideration to ecological sustainability and human livelihoods.

While there are many ways in which this diagnostic framework may be operationalized, we describe our approach to data collection and data treatment in the following section.

\section{MAKING THE DIAGNOSTIC APPROACH TO ADAPTIVE COMANAGEMENT OPERATIONAL-METHODS AND MEASURES}

We closely applied the diagnostic framework (Fig. 1, Table 1) to investigate cases of ACM in four biosphere reserves in Canada and Sweden. Biosphere reserves are designated by the United Nations Educational, Scientific and Cultural Organization (UNESCO) as sites where conservation, development, and logistical support are pursued in concert. They are described as "learning sites for sustainable development" (UNESCO 2008:5), and as such offer cases where the features of ACM are exhibited. Biosphere reserves generally have a single manager or coordinator, and engage multiple, often diverse stakeholders in governance of a region, though no formal authority is held by biosphere reserves in Canada and Sweden. We used a mixed methods approach for data collection. Quantitative and qualitative approaches provided opportunities to collect data related to all first-, second-, and third-tier variables, and many of the methods used collected data for multiple first-tier variables (see Appendix 1 for variable map showing the linkages between instruments and variables in the diagnostic framework). The instruments developed for the purposes of collecting data related to the variables identified in the diagnostic framework are provided in the appendices and are referred to in this section.

Documents were requested from the manager in each case to collect data about the setting and antecedents (specifically the activities that formed each case). Additional documents were collected by desktop study, including government documents and scholarly literature related to the cases, to gain a broader understanding of the setting.

A social-ecological inventory (SEI) was conducted with managers and individuals they identified as participants in governance. The SEI is a semistructured interview tool developed by Schultz et al. (2007) that was designed to capture the activities being undertaken in steward groups and who is involved, thereby bridging social and ecological systems, and explicitly considering local knowledge. In this project, the SEI was used to capture qualitative data about the actors engaged in biosphere reserve governance, including motivations for involvement, activities they have engaged in, perceptions of prioritization of biosphere reserve goals, and any concerns about the biosphere reserve generally, thereby providing data related primarily to the second-tier variables corresponding to setting and antecedents in Table 1 (see Appendix 2 for the instrument). Respondents were also asked to identify any other individuals involved that should be included in the study. Thus, a snowball sampling strategy was employed in addition to the lists provided by the managers. All interviews were audio-recorded and transcribed.

Indepth interviews were administered to key individuals in each case. Questions focused on gaining insights about the setting (e.g., the history of the cases) and process (e.g., how learning occurred and how opportunities were created, networks and how they formed, skills and strategies used by the managers to overcome challenges and be successful) (see Appendix 3 for the instrument). All interviews were audio-recorded and transcribed.

Questionnaires were administered at two times to all actors involved in biosphere reserve governance: first at the outset of the study, and second, 1.5 years later to capture change over time and feedbacks. The questionnaire included a combination of open and closed Likert-type questions, as well as a social network section where respondents provided information regarding with whom they communicate about the biosphere reserve (Plummer et al. 2014). The instrument collected data related to the first-tier variables of antecedents, process, and outcomes in the diagnostic framework, and probed the second- and third-tier variables therein (Fig. 1, Table 1). Specifically, it queried perceptions of collaborative qualities (Plummer and Armitage 2007, Plummer et al. 2014, Sandström et al 2014, Birnbaum et al. 2015), learning (Baird et al. 2014, Plummer et al. 2014), results (Plummer and Armitage 2007, Plummer et al. 2014), and effects (Plummer and Armitage 2007, Plummer et al. 2014). The first and second questionnaire instruments were very similar, but some questions were omitted where longitudinal data were not required, and some questions were altered slightly to capture data since the first questionnaire. Quantitative data were imported into SPSS 21 (IBM Inc.). The first questionnaire is provided in Appendix 4.

The instruments described were prepared in English and translated to Swedish, using the most similar terms in meaning possible in the translation. Qualitative responses from all instruments were imported into NVivo 11 (QSR International) for coding. An extensive codebook was created using the first-, second-, and thirdtier variables in Table 1 (Appendix 5). This codebook was used to code all documents and qualitative responses for all relevant codes. Swedish responses were coded by a Swedish researcher using the English codebook. Swedish responses were translated to English as needed for further analysis.

\section{Data types collected using the diagnostic framework}

Qualitative and quantitative data were collected in relation to the variables identified in Table 1, using the instruments described. The breadth of data collected by using this approach provides opportunities to measure and build an understanding of ACM and the context within which it is situated. The depth of data collected (third-tier variables in most cases) allows specific variables of interest to be examined in detail. Databases of this sort are needed for consistent and systematic analysis of ACM (Plummer et al. 2012). The diagnostic framework presents the architecture needed for creating and maintaining a growing database of case study data that responds to this need and provides opportunities for new analytical approaches for ACM. 
Table 2. Insights from analyses undertaken using the diagnostic framework for adaptive comanagement (ACM).

\begin{tabular}{lll}
\hline \hline Analytical approach & Insights & References \\
\hline $\begin{array}{l}\text { Quantitative } \\
\text { Structural equation modeling }\end{array}$ & $\begin{array}{l}\text { Provided insights into the respective roles of } \\
\text { stakeholder engagement, collaboration, and } \\
\text { learning on the evaluation of outcomes by } \\
\text { stakeholders; evidence supports the importance } \\
\text { of these processes as part of the larger ACM } \\
\text { approach }\end{array}$ & $\begin{array}{l}\text { Plummer et al. (2017); Armitage et al., } \\
\text { unpublished manuscript; Plummer et al., } \\
\text { unpublished manuscript }\end{array}$ \\
$\begin{array}{l}\text { Highlighted the dynamic and cyclical nature of } \\
\text { ACM in relation to coordination and } \\
\text { collaboration and perceptions of risk }\end{array}$ & Bodin et al., unpublished manuscript \\
$\begin{array}{l}\text { Qualitative } \\
\text { Process tracing }\end{array}$ & $\begin{array}{l}\text { Focused on antecedents and identified causal } \\
\text { mechanisms that led to ACM }\end{array}$ & Baird et al., unpublished manuscript \\
Content analysis & $\begin{array}{l}\text { ECM thasized antecedent variables associated with } \\
\text { ACMable governing with multiple goals }\end{array}$ & Schultz et al., unpublished manuscript \\
& & \\
\hline
\end{tabular}

\section{Variable measures and validation}

Measures for each of the variables in Table 1 and those previously described were developed and tested. Each (at the second-tier level) is described briefly.

\section{Qualitative data}

Each respondent identified their primary job and affiliation in open questions in the questionnaire, and from that information, stakeholder type and level, and diversity of these third-tier variables was determined using a preset list of potential options. Activities were requested in an open question in the questionnaire, and were coded according to type and frequencies used in subsequent analyses. Practices were gleaned from the SEI and deep interviews via qualitative data coding.

\section{Quantitative data}

Several closed questions probed the process and outcomes variables shown in Table 1. Quantitative data were assembled into validated and tested measures of second- and third-tier variables using Cronbach's alpha and exploratory and confirmatory factor analysis. Each variable was confirmed as internally valid, and thus may be used as reliable measures in other studies. Of course, the opportunity exists to delve deeper into third-tier variables as well (i.e., identify and test fourth-tier variables) using a similar approach. Social network data were prepared in a matrix format and imported into Ucinet 6 (Analytic Technologies Inc.). Measures of ego network size and diversity were obtained from these data. The questions in the questionnaire that corresponded to the third-tier variables are identified in Appendix 4.

\section{Potential analyses}

From the robust collection of data, a multifaceted understanding of ACM may start to develop. In particular, the multitier nature of the variables in the framework creates a platform for which to move forward with a range of analyses. These may be indepth investigations of a single variable using qualitative (e.g., process tracing) or quantitative (e.g., exponential random graph modeling) methods. Importantly, the validated measures developed from the collected data also make possible relational analyses. These measures can be used to examine relationships among variables and feedbacks in ACM (e.g., via structural equation modeling approaches). These examples represent approaches taken in our own research, and a summary of insights gained from them is provided in Table 2 . Considered together, the insights illuminate important nuances of the tenets of ACM and yield policy-relevant findings (Plummer et al., unpublished manuscript).

The example analyses provided represent only a subset of potential approaches that could be taken to analyze data collected. As the database grows with the addition of more data from case studies, it creates a substantial opportunity for systematic analytical approaches in ACM research.

\section{REFLECTIONS AND LOOKING FORWARD}

The state of ACM scholarship is indicative of an emerging and quickly growing area of scholarship. Despite illuminating some very valuable insights, Plummer et al. (2012) were not able to draw robust evidenced-based findings and address several important questions from a systematic review of the ACM literature due to conceptual imprecision and methodological inconsistencies. Such uncertainty often prompts calls for novelty and/or the creation of new frameworks - in this specific situation, a diagnostic approach was identified as one way to systematize analyses of ACM (Plummer et al. 2012, 2014).

Drawing upon our multiyear research project to create, test, and refine the diagnostic approach for ACM, we have (1) set out a common framework and nomenclature with which to systematically compare experiences with ACM (and similar approaches), and (2) provided corresponding methods and measures to facilitate research in a variety of empirical settings over time. The diagnostic approach and framework put forth serve to move ACM research forward in a new direction. The framework overcomes past imprecision and inconsistencies to enable the systematic culmination of knowledge and deriving causal inferences essential without sacrificing flexibility. We demonstrate that both quantitative and qualitative approaches to data collection and analysis may be employed using the framework, and that insights may be drawn from individual studies or identified by synthesizing the findings of diverse research efforts. 
Several key insights come from our multiyear efforts to move from appeal and proposal of a diagnostic approach to trial and establishment. First, the steps set out in the diagnostic framework facilitated systematic inquiry while maintaining an awareness of and sensitivity to context. Agreeing upon an established nomenclature in advance and adhering to it throughout all stages of the inquiry was essential. Common nomenclature of the phenomenon (ACM) and tiers of variables (setting, antecedents, process attributes, outcomes) served as conceptual anchors, which were routinely revisited throughout fieldwork and data collection. Identifying tiers of variables as well as their relationship at higher levels, using the framework, facilitated analysis within and across variables. We developed measures of variables that were subsequently tested and confirmed to be internally valid for major first-, second-, and third-tier variables related to the main process variables of ACM (learning, collaboration) and social and ecological outcomes. Establishing methods and measures a priori was necessary because they made the diagnostic framework operational. This does create a tension, given the significant benefits of a more grounded research approach in which participants help determine the validity of measures given their local circumstances. However, a priori identification of methods and measures permitted the multiyear inquiry to be undertaken in a robust and consistent manner across multiple cases in different countries. The measures, in particular, made possible comparative analysis between/among the cases and summative analysis involving all cases in relation to understanding specific variables central to ACM as well as linkages among variables at a range of levels.

Our experience has also exposed some noteworthy challenges, which should be anticipated but which also can be managed. Systematically investigating ACM in a consistent manner in a variety of situations lies at the heart of the diagnostic approach. However, this is a challenging task that requires constant attention and commitment. Working in varied contexts and in different cultures necessitates going well beyond the surface of scholarly constructs to carefully consider how ideas and terms are appropriate or may be interpreted. Even with the utmost commitment to ensure consistency, the attendant realities of conducting primary research with people poses a persistent challenge to the maintenance of a consistent approach. As well, implementation of the diagnostic approach used multiple methods from a myriad of sources and yielded a significant amount of qualitative and quantitative data. Forethought about data organization and ongoing attention to data management are paramount so that treatment of data will be tailored to the specific research question being posed. For example, in modeling causal relationships in ACM using path analysis, it is important to have three to five indicators of a single variable (Plummer et al., unpublished manuscript). In such a case, selecting appropriate indicators (e.g., third-tier variables to represent a second-tier variable) is important and requires consideration prior to engaging in the research.

In moving forward, the diagnostic approach to ACM we presented offers a foundation to make rigorous comparisons across settings, draw robust evidence-based findings that link actions to outcomes, and ultimately, advance theoretical development. The framework offers opportunities to undertake deep inquiries into specific variables, build an understanding of the tiered nature of variables, and as more data are collected using this approach, the power to test more nuanced linkages among variables. We offer the instruments used to collect data related to the framework (in the appendices) as an inspiration for others' work in ACM to facilitate cross-case comparisons and to continue to build the literature in this field. The diagnostic framework complements other types of approaches to investigate ACM and will not always be desirable or appropriate. Nevertheless, it affords a means by which progress may be made to address ongoing challenges that confront the evolution of adaptive comanagement. And finally, as stated earlier, although our focus has been on ACM, we hope that the value of the diagnostic framework will extend to scholars who are not entirely focused on ACM per se, but in conceptually similar and perhaps even partly overlapping collaborative natural resource management/ governance scholarly frameworks.

Responses to this article can be read online at: http://www.ecologyandsociety.org/issues/responses. $\mathrm{php} / 9436$

\section{Acknowledgments:}

This research has been made possible by funding received from Vetenskapsrådet, the Swedish Research Council, grant 2012-5498. We also acknowledge funding by MISTRA through a core grant to Stockholm Resilience Centre. We gratefully acknowledge participation in this research by the managers and others from the Frontenac Arch, Georgian Bay, Kristianstads Vattenrike, and Östra Vätterbranterna Biosphere Reserves. Our appreciation is also extended to our colleague Beatrice Crona for her constructive insights with conceptualizing the research project. Finally, we wish to thank Disa Hansson, Malena Heinrup, Katrina Krievins, Flor de Luna Estrada, and Kerrie Pickering for research assistance.

\section{LITERATURE CITED}

Argyris, C., and D. Schön. 1974. Theory in practice: increasing professional effectiveness. Josey-Bass, San Francisco, California, USA.

Armitage, D., F. Berkes, and N. Doubleday, editors. 2007. Adaptive co-management: collaboration, learning, and multi-level governance. University of British Columbia Press, Vancouver, Canada.

Armitage, D. R., R. Plummer, F. Berkes, R. I. Arthur, A. T. Charles, I. J. Davidson-Hunt, A. P. Diduck, N. C. Doubleday, D. S. Johnson, M. Marschke, P. McConney, E. W. Pinkerton, and E. K. Wollenber. 2009. Adaptive co-management for socialecological complexity. Frontiers in Ecology and the Environment 7(2):95-102. http://dx.doi.org/10.1890/070089

Baird, J., R. Plummer, and Ö. Bodin. 2016. Collaborative governance for climate change adaptation in Canada: experimenting with adaptive co-management. Regional Environmental Change 16(3):747-758. http://dx.doi.org/10.1007/ s10113-015-0790-5

Baird, J., R. Plummer, C. Haug, and D. Huitema. 2014. Learning effects of interactive decision-making processes for climate 
change adaptation. Global Environmental Change 27:51-63. http://dx.doi.org/10.1016/j.gloenvcha.2014.04.019

Berkes, F., D. Armitage, and N. Doubleday. 2007. Synthesis: adapting, innovating, evolving. Pages 308-327 in D. Armitage, F. Berkes, and N. Doubleday, editors. Adaptive co-management: collaboration, learning and multi-level governance. University of British Columbia Press, Vancouver, British Columbia, Canada.

Birnbaum, S., Ö. Bodin, and A. Sandstöm. 2015. Tracing the sources of legitimacy: the impact of deliberation in participatory natural resource management. Policy Sciences 48(4):443-461. http://dx.doi.org/10.1007/s11077-015-9230-0

Conley, A., and M. A. Moote. 2003. Evaluating collaborative natural resource management. Society \& Natural Resources 16:371-386. http://dx.doi.org/10.1080/08941920309181

Cox, M. 2011. Advancing the diagnostic analysis of environmental problems. International Journal of the Commons 5 (2):346-363. http://dx.doi.org/10.18352/ijc. 273

Diduck, A. 2010. The learning dimension of adaptive capacity: untangling the multi-level connections. Pages 199-221 in D. Armitage and R. Plummer, editors. Adaptive capacity and environmental governance. Springer Verlag, New York, New York, USA. http://dx.doi.org/10.1007/978-3-642-12194-4 10

Fabricius, C., and B. Currie. 2015. Adaptive co-management. Pages 147-179 in C. R. Allen, and A. S. Garmestani, editors. Adaptive management of social-ecological systems. Springer Science and Business Media, Dordrecht, The Netherlands. http:// dx.doi.org/10.1007/978-94-017-9682-8_9

Fazey, I., J. A. Fazey, and D. M. A. Fazey. 2005. Learning more effectively from experience. Ecology and Society 10 (2):4. http:// dx.doi.org/10.5751/es-01384-100204

Folke, C., T. Hahn, P. Olsson, and J. Norberg. 2005. Adaptive governance of social-ecological systems. Annual Review of Environment and Resources 30:441-473. http://dx.doi.org/10.1146/ annurev.energy.30.050504.144511

Guerry, A. D., S. Polasky, J. Lubchenco, R. Chaplin-Kramer, G. C. Daily, R. Griffin, M. Ruckelshaus, I. J. Bateman, A. Duraiappah, T. Elmqvist, M. W. Feldman, C. Folke, J. Hoekstra, P. M. Kareiva, B. L. Keeler, S. Li, E. McKenzie, Z. Ouyang, B. Reyers, T. H. Ricketts, J. Rockstrôm, H. Tallis, and B. Vira. 2015. Natural capital and ecosystem services informing decisions: from promise to practice. Proceedings of the National Academy of Sciences of the United States of America 112(24):7348-7355. http://dx.doi.org/10.1073/pnas.1503751112

Holling, C. S., and G. K. Meffe. 1996. Command and control and the pathology of natural resource management. Conservation Biology 10(2):328-337. http://dx.doi.org/10.1046/ j.1523-1739.1996.10020328.x

Huitema, D., E. Mostert, W. Egas, S. Moellenkamp, C. PahlWostl, and R. Yalcin. 2009. Adaptive water governance: assessing the institutional prescriptions of adaptive (co-)management from a governance perspective and defining a research agenda. Ecology and Society 14(1):26. http://dx.doi.org/10.5751/es-02827-140126

Innes, J. E., and D. E. Booher. 1999. Consensus building and complex adaptive systems: a framework for evaluating collaborative planning. Journal of the American Planning Association 65(4):412-423. http://dx.doi.org/10.1080/01944369908976071

Lockwood, M., J. Davidson, A. Curtis, E. Stratford, and R. Griffith. 2010. Governance principles for natural resource management. Society \& Natural Resources 23:986-1001. http:// dx.doi.org/10.1080/08941920802178214

McGinnis, M. D., and E. Ostrom. 2014. Social-ecological system framework: initial changes and continuing challenges. Ecology and Society 19(2):30. http://dx.doi.org/10.5751/ES-06387-190230

Meinzen-Dick, R. 2007. Beyond panaceas in water institutions. Proceedings of the National Academy of Sciences of the United States of America 104(39):15200-15205. http://dx.doi.org/10.1073/ pnas.0702296104

Olsson, P., C. Folke, and F. Berkes. 2004. Adaptive comanagement for building resilience in social-ecological systems. Environmental Management 34(1):75-90. http://dx.doi.org/10.1007/s00267-003-0101-7

Ostrom, E. 2007. A diagnostic approach for going beyond panaceas. Proceedings of the National Academy of Sciences of the United States of America 104(39):15181-15187. http://dx.doi. org/10.1073/pnas.0702288104

Ostrom, E. 2009. A general framework for analyzing sustainability of social-ecological systems. Science 325 (5939):419-422. http://dx.doi.org/10.1126/science.1172133

Plummer, R. 2009. The adaptive co-management process: an initial synthesis of representative models and influential variables. Ecology and Society 14(2):24. http://dx.doi.org/10.5751/ es-03130-140224

Plummer, R., and D. Armitage. 2007. A resilience-based framework for evaluating adaptive co-management: linking ecology, economics and society in a complex world. Ecological Economics 61(1):62-74. http://dx.doi.org/10.1016/j.ecolecon.2006.09.025

Plummer, R., J. Baird, A. Dzyundzyak, L. Schultz, D. Armitage, Ö. Bodin, and L. Schultz. 2017. Is adaptive co-management delivering? Examining relationships between collaboration, learning and outcomes in UNESCO biosphere reserves. Ecological Economics 140:79-88. http://dx.doi.org/10.1016/j. ecolecon.2017.04.028

Plummer, R., B. Crona, D. R. Armitage, P. Olsson, M. Tengö, and O. Yudina. 2012. Adaptive comanagement: a systematic review and analysis. Ecology and Society 17(3):11. http://dx.doi. org/10.5751/es-04952-170311

Plummer, R., L. Schultz, D. Armitage, Ö. Bodin, B. Crona, and J. Baird. 2014. Developing a diagnostic approach for adaptive comanagement and considering its implementation in biosphere reserves. Beijer Discussion Paper Series No. 245, Beijer Institute of Ecological Economics, Stockholm, Sweden.

Reed, M. S. 2008. Stakeholder participation for environmental management: a literature review. Biological Conservation 141:2417-2431. http://dx.doi.org/10.1016/j.biocon.2008.07.014

Reed, M. S., A. C. Evely, G. Cundill, I. Fazey, J. Glass, A. Laing, J. Newig, B. Parrish, C. Prell, C. Raymond, and L. C. Stringer. 2010. What is social learning? Ecology and Society 15(4):r1. [online] URL: http://www.ecologyandsociety.org/vol15/iss4/ resp1/ 
Sandström, A., B. Crona, and Ö. Bodin. 2014. Legitimacy in comanagement: the impact of preexisting structures, social networks and governance strategies. Environmental Policy and Governance 24(1):60-76. http://dx.doi.org/10.1002/eet.1633

Schultz, L., and A. Duit. 2011. Participation, adaptive comanagement, and management performance in the world network of biosphere reserves. World Development 39(4):662-671. http://dx.doi.org/10.1016/j.worlddev.2010.09.014

Schultz, L., C. Folke, and P. Olsson. 2007. Enhancing ecosystem management through social-ecological inventories: lessons from Kristianstads Vattenrike, Sweden. Environmental Conservation 34 (2):140-152. http://dx.doi.org/10.1017/s0376892907003876

United Nations Educational, Scientific and Cultural Organization (UNESCO). 2008. Madrid Action Plan for Biosphere Reserves 2008-2013. UNESCO and MAB, Paris, France. [online] URL: http://unesdoc.unesco.org/ images/0016/001633/163301e.pdf

Webler, T., S. Tuler, and R. Krueger. 2001. What is a good public participation process? Five perspectives from the public. Environmental Management 27:435-450. http://dx.doi.org/10.1007/ $\underline{\mathrm{s} 002670010160}$

Whaley, L., and E. K. Weatherhead. 2014. An integrated approach to analyzing (adaptive) comanagement using the "politicized" IAD framework. Ecology and Society 19(1):10. http://dx.doi.org/10.5751/ES-06177-190110 
Appendix 1. Variable map

Please click here to download file 'appendix1.xlsx'. 
Appendix 2. Social-ecological inventory semi-structured interview script

1. Can you tell me about yourself and the organization you represent (if any and the position you represent)?

2. a. What motivates you to be involved in biosphere reserve governance?

b. How did you get involved?

c. For how long have you been involved?

3. Are you/your organization involved in any activities related to the biosphere reserve? Tell me about those activities. (Not just any activity within the reserve's geographical area but activities connected to the organization/management).

4. a. What do you perceive are the general goals of the biosphere reserve?

b. What do you think the biosphere reserve should prioritize among those goals?

c. Are there other goals you think the biosphere reserve should work for?

5. Is there anything in the biosphere reserve that concerns you?

(Could be concerns about the biosphere reserve generally - i.e. activities going on within the geographical area: mining/forestry/conservation projects... - and concerns about biosphere reserve governance/management: lack of leadership/lack of engagement/too many people involved etc.)

6. Who else do you think we should talk to that are involved in and set the direction for the management/governance of the biosphere reserve?

7. Can you identify anyone else we should speak with regarding the biosphere reserve? 
Appendix 3. In-depth interview script.

\section{Questions:}

1. Could you please tell me the history of this biosphere reserve and your own engagement with it? Here, we will probe the perceived vision for the biosphere reserve, the sources of personal commitment, how the governance network was formed and how it has changed over the years, as well as key moments of learning related to biosphere reserve management

2. If you think back at a project that was particularly successful, what would you say were the key factors of success?

a. Focusing on the network of people involved in making the project successful, and what you did as a manager to build and support this network, who were involved and why them? How did they become involved?

b. Focusing on the learning that happened during the project - how would you describe it (who learned, about what, and how)? What did you do to enhance learning opportunities?

3. If you think back at a project that was particularly challenging, can you tell me how you acted to overcome these challenges?

a. Focusing on the network of people involved in the project and what you did as a manager to build and support this network, who were involved and why them? How did they become involved?

b. Focusing on the learning that happened during the project, how would you describe it (probing who learned, about what, and how)? What did you do to enhance learning opportunities?

4. What would you say are your most important skills as a biosphere reserve manager?

5. How have you developed these skills? 


\section{Appendix 4. Questionnaire}

\section{Section 1. Activities}

Respondents asked to identify all the activities in which they participated in the following categories (open ended question):

1. Preparation of biosphere reserve related materials

2. Practical actions on the landscape

3. Projects that involve monitoring

4. Social events

5. Mapping of the biosphere reserve

6. Activities related to management and planning

7. Activities related to governance or decision making

Section 2. Perspectives on the biosphere reserve

Respondents asked to identify (open ended question):

1. The main values of the biosphere reserve landscape that they would like to maintain

2. The most important threats to those values

\section{Section 3. Process questions}

All items were assessed using a five-point Likert response scale ( $1=$ strongly disagree; $5=$ strongly agree).

Table A4.1

\begin{tabular}{|c|c|}
\hline Item & \\
\hline Collaborative qualities items & \\
\hline $\begin{array}{l}\text { The process has been characterized by widely differing opinions regarding the view on problems, } \\
\text { goals and strategies. }\end{array}$ & $\begin{array}{l}\text { Pluralism and } \\
\text { linkages }\end{array}$ \\
\hline $\begin{array}{l}\text { The process has been characterized by deep conflict (i.e., conflict that is strong and enduring) } \\
\text { between the actors involved. }\end{array}$ & $\begin{array}{l}\text { Open } \\
\text { communication, } \\
\text { negotiation and } \\
\text { mutual respect }\end{array}$ \\
\hline $\begin{array}{l}\text { The process gives all actors equal opportunities to state their opinion and to influence the } \\
\text { outcome. }\end{array}$ & Legitimacy \\
\hline The process is transparent. & Legitimacy \\
\hline The process encourages reasonable and constructive discussions. & $\begin{array}{l}\text { Open } \\
\text { communication, } \\
\text { negotiation and } \\
\text { mutual respect }\end{array}$ \\
\hline The process encourages new solutions. & $\begin{array}{l}\text { Transactive } \\
\text { decision- } \\
\text { making }\end{array}$ \\
\hline The process is characterized by trust and confidence among the involved actors. & $\begin{array}{l}\text { Open } \\
\text { communication, } \\
\text { negotiation and } \\
\text { mutual respect }\end{array}$ \\
\hline
\end{tabular}


Over time, the process has changed my view on how management of the BR should be best organized.

Some individuals have been/are particularly important for facilitating learning from our activities and discussions.

Some actors have had/continue to have a disproportionately large influence on decisions (e.g. have tended to dominate decision making processes).

Learning items

My understanding of the ecological conditions of the BR has increased due to my involvement in the BR management process.

My understanding of the social conditions of the BR have increased due to my involvement in the BR management process.

My knowledge of the problems and challenges of the BR has increased due to my involvement in the BR management process.

My knowledge of the opportunities of the BR has increased due to my involvement in the BR management process.

A majority of my current knowledge about the landscapes of the BR comes from my involvement with BR management.

The BR management process has helped me understand the perspective of others.

The BR management process has become more important over time.

My views on the BR have led me to act in surprising or new ways.

My views on the BR are similar to those of others involved in the BR management process.

Over time, the process has changed my view on which goals should steer the management of the area.

Involvement in the BR has enhanced my cooperation/coordination with other individuals and groups/organizations within the BR.

Involvement in the BR has enhanced my cooperation/coordination with other individuals and groups/organizations outside the BR.

Involvement in the BR has enhanced my communication with other individuals and groups/organizations within the BR.

Involvement in the BR has enhanced my communication with other individuals and groups/organizations outside the BR.

I have increased my understanding/acceptance of other actors' perspectives as a result of my involvement in the BR process.
Transactive

decision-

making

Pluralism and

linkages

Legitimacy
Cognitive

Cognitive

Cognitive

Cognitive

Cognitive

Normative

Normative

Normative

Normative

Normative

Relational

Relational

Relational

Relational

Relational

\section{Section 4. Network question}

Respondents were provided with a list of actors engaged in the biosphere reserve (not provided here for reasons of confidentiality). For each person identified on the list, respondents were asked to identify how often they exchanged information and/or knowledge related to the governance and management of the biosphere reserve, and how often they coordinated actions related to the governance and management of the biosphere reserve. Options for each were: often, sometimes or never.

\section{Section 5. Outcomes questions}

All items were assessed using a five-point Likert response scale ( $1=$ strongly disagree; $5=$ =strongly agree). Note that the third-tier variable associated with each item is identified on the right side of the table. 
Table A4.2

\begin{tabular}{lc}
\hline \hline Item & Associated third-tier variable \\
\hline
\end{tabular}

Results items

Please indicate the extent to which you feel the process of collaborative management and governance has resulted in:

Enhanced legitimacy (i.e. a more transparent, equitable and fair processes for decision-making) $\quad 1^{\text {st }}$ order,

Resolution of conflicts among different interests and actor groups within the BR

Intangible

$1^{\text {st }}$ order,

Intangible

Greater support by those not involved in the process of collaborative management and

$2^{\text {nd }}$ order

governance for BR decisions

Greater support by those not involved in the process of collaborative management and

governance for BR future activities

New co-operative undertakings with partners within the geographical boundary of the BR

New co-operative undertakings with partners beyond the geographical boundary of the BR

Ability to engage with a broader set of issues and challenges within the BR (i.e., increasing scope and mandate)

Greater efficiency of the group involved in BR governance and management in making decisions

and responding to issues

Greater flexibility of the group involved in BR governance and management with how challenges

are addressed

Informal agreements of how to address an issue

Novel approaches to solving problems within the group involved in BR governance and

management

Contemplation and questioning of routines, values and governance by the group involved in BR

governance and management

Fostering dialogue between different interests

$2^{\text {nd }}$ order

$1^{\text {st }}$ order,

Tangible

$2^{\text {nd }}$ order

$1^{\text {st }}$ order,

Intangible

$1^{\text {st }}$ order,

Intangible

$1^{\text {st }}$ order,

Intangible

$1^{\text {st }}$ order,

Tangible

$1^{\text {st }}$ order,

Intangible

$1^{\text {st }}$ order,

Intangible

$1^{\text {st }}$ order,

Intangible

\section{Effects items}

Please indicate the extent to which you feel the process of collaborative management and governance has effected:

Ecological sustainability within the BR (e.g., biodiversity protection, maintaining ecosystem services)

Ecological sustainability beyond the BR (e.g., biodiversity protection, maintaining ecosystem services)

Enhancements in wellbeing for those living within the geographical boundary of the BR

Ecological

components

Ecological

components

Livelihood

assets

Decreases in vulnerability for those living within the geographical boundary of the BR

Livelihood

assets

More sustainable resource use within the BR

Ecological

components

Improvements in human capital (e.g., skills, capacity) by for those living within the geographical boundary

Livelihood

assets

Improvements in social capital (e.g., trust, relationships, working together) by those involved in the collaborative management and governance of the BR.

Livelihood

assets

Improvements in physical capital (e.g., infrastructure, communication systems, community

facilities) by those involved in the collaborative management and governance of the BR.

Livelihood

assets

Stimulating sustainable economic development (e.g. improvements in economic opportunities for

individuals and communities such as employment opportunities, income improvements) within

Livelihood

the geographical boundary of the BR.

assets 


\section{Appendix 5. Codebook}

Note: $\mathrm{BR}=$ Biosphere Reserve

\section{Component 1: Setting}

Table A5.1 Setting considerations for adaptive co-management initiatives in biosphere reserves (adapted for codebook)

\begin{tabular}{|c|c|}
\hline Variable & Description \\
\hline \multicolumn{2}{|c|}{$2^{\text {nd }}$ tier variable: $\mathrm{BIOPHYSICAL}$} \\
\hline $3^{\text {rd }}$ tier variable & Description \\
\hline REGION & $\begin{array}{l}\text { Biome and ecoregion; classification systems, species at risk, buffer zone, transiti } \\
\text { zone, invasive species }\end{array}$ \\
\hline AREA & $\begin{array}{l}\text { Size of area of BR; physical layout of the area, including geographical coordinat } \\
\text { street and road names that define the entire or parts of the BR }\end{array}$ \\
\hline \multicolumn{2}{|c|}{$2^{\text {nd }}$ tier variable: SOCIAL } \\
\hline $3^{\text {rd }}$ tier variable & Description \\
\hline POPULATION & Population (size) and density \\
\hline PROFILE & Socio-economic profile (e.g., demographics, employment) \\
\hline \multicolumn{2}{|c|}{$2^{\text {nd }}$ tier variable: Social-ecological } \\
\hline $3^{\text {rd }}$ tier variable & Description \\
\hline LAND USE & Current land uses (e.g., agriculture, golf courses, forest cover, urban areas) \\
\hline
\end{tabular}


EMBEDDEDNESS Dependence/reliance on local ecosystems for income/identity (embeddedness) (social and/or economic element and ecological element)

$2^{\text {nd }}$ tier variable: biosphere reserve

Sub-category code Description

GOALS Visions and goals for BRs

STRUCTURE Organizational structure

HISTORY History (social history, development of the BR - prior to BR designation including social, geological, embeddedness), policies

ACTIVITIES Activities that occur within the biosphere reserve

\section{Component 2: Practices and activities}

Table A5.2

\begin{tabular}{|c|c|c|}
\hline Variable & Description & Key words, phrases \\
\hline $2^{\text {nd }}$ tier variable: PRACTICES & & \\
\hline $3^{\text {rd }}$ tier variable & Description & Key words, phrases \\
\hline SPACE & Spaces for interaction & $\begin{array}{l}\text { Spaces where stakeholders meet (can be a physical } \\
\text { space, or an event or meeting) (from Crona and } \\
\text { Parker 2012) } \\
\text { Include virtual spaces (Facebook pages, webinars, } \\
\text { blogs, etc.) }\end{array}$ \\
\hline BOUNDARY OBJECT & Boundary objects & $\begin{array}{l}\text { Objects that allow "members of different } \\
\text { communities to interact and coordinate their efforts } \\
\text { despite their sometimes divergent perceptions of } \\
\text { the object... (e.g., models, classification systems, } \\
\text { interactive maps) (Crona and Parker 2012) }\end{array}$ \\
\hline
\end{tabular}


$2^{\text {nd }}$ tier variable: ACTIVITIES

$3^{\text {rd }}$ tier variable

PLANNING

IMPLEMENTATION

MONITORING

ASSESSMENT
Description

Planning and decision making

Implementation and

experimentation

Monitoring

Assessment and evaluation
Code mentions of actual objects. For example, if a passage indicates that one of the activities that occurred during a meeting was a mapping exercise, the map would be considered a boundary object, and would be coded as such

Key words, phrases associated

Text that refers to the act/process of making decisions about activities that will be undertaken, creating documents that outline goals/actions Text that refers to the act/process of implementing plans and decisions, as well as actions undertaken for the purpose of experimentation (adaptive management)

Text that refers to the act of monitoring the effects/outcomes from plans and actions taken Text that refers to the act of assessing and/or evaluating effects/outcomes of plans and actions taken

\section{Component 3: Results}

Table A5.3 Adapted from Plummer and Armitage (2007)

\begin{tabular}{lll}
\hline \hline Variable & Description & Definition and key words, phrases \\
\hline $3^{\text {rd }}$ tier variable: FIRST ORDER & \\
$4^{\text {th }}$ tier variable & Description & Definition and key words, phrases \\
PLAN & Resource management plans & References to resource management plans that have been \\
& developed by the BRs
\end{tabular}




RESOLUTION OR
AGREEMENT
COLLECTIVE
ACTION

STATEMENT OF

ACTIONS

SANCTIONS

INSTUTIONAL ARRANGEMENTS

\section{COOPERATIVE \\ UNDERTAKINGS}

LEGITIMACY

ADAPTIVE

CAPACITY

SOC/HUMAN
CAPITAL
PROBLEM
SOLVING
QUESTIONING

SOC/HUMAN

PROBLEM

QUESTIONING
Resolution of conflict/dispute and/or agreement regarding resource issue

Undertaking collective actions to resolve problems

\section{Codified statement of actions \\ Agreed upon sanctions}

New or modification of institutional arrangement(s)

New cooperative undertakings

Enhanced legitimization for policies and actions

Greater adaptive capacity

Social and human capital

Creative ideas for solving problems

Encourages contemplation and questioning of routines, values and governance
References to resolutions of conflicts or disputes; references to agreements regarding a resource issue

References to collective actions that have been/are being undertaken in the BR for the purpose of resolving problems

For example, new partnerships, coordination and / or joint action; implementation of agreements within the BR

References to, or evidence of, a formal statement with a systematic arrangement of actions to be undertaken within the BR References to agreed upon rules to address negligent behaviour/action

References to formal or informal new policies, strategies, organization, etc., or modification to existing institutional arrangements

New physical projects undertaken via a cooperative effort within the BR

References to just and fair actions and outcomes (E.g., satisfaction with a policy because all stakeholder viewpoints were expressed and considered)

References to increases in adaptive capacity specifically, or: increased ability to deal with change and uncertainty greater ability to nurture diversity (social and/or ecological) greater ability to combine different knowledge types for learning increased opportunities for self-organization

networks, groups, rules, norms, sanctions; relationships of trust, reciprocity, exchange

References to creativity or new, different, innovative ideas for problem solving identified/developed within the BR

Explicit references by respondents of opportunities to question/contemplate their own values/routines or the values/routines/governance of the BR resulting from the BR ACM process. 
DECISION MAKING Improved decision making

UNDERSTANDING OF INTERACTIONS

Changes in understanding of human-environment interactions

\section{FLEXIBILITY}

OTHER

\section{Enhanced flexibility}

Other first order outcomes that do not fit in the existing sub-categories

$3^{\text {rd }}$ tier variable: SECOND ORDER
$4^{\text {th }}$ tier variable
Description

COOPERATIVE

UNDERTAKINGS

LEARNING AND

ENGAGEMENT

PERCEPTIONS AND Changes in perceptions (attitudes) and actions

BEHAVIOURS
New co-operative undertakings beyond the specific issue

Extends engagement and learning across scales (behaviours)
And/or, references to opportunities taken to do this within the governance of the BR in associated documents (strategic plans, etc.)

Explicit references to improvements to the decision-making process within the BR (E.g. of a generic statement a respondent might make that would be coded here: 'We found that the decision to undertake action $\mathrm{x}$ was easier to make as a result of recent changes to the governance structure of the BR')

Note: This is different than any mention of decision-making identified above in Component 2 where all acts of planning and decision making are coded)

References to changes in the way individuals or groups understand human-environment interactions (e.g., as a result of increased knowledge, experience, diversity of viewpoints available to them)

References specifically describing increased flexibility in responses to issues/problems, or actions taken within the BR

Definition and key words, phrases (from Innes and Booher [1999])

For example, new partnerships, coordination and / or joint action; implementation of agreements that extend beyond the BR For example, learning that extends into the broader community, this can be planned engagement/learning, or can be emergent Evidence of new / different attitudes and behaviours by individuals beyond the BR. This may be evident from interview responses (hypothetical example: 'I found that, as a result of our efforts in the BR, people in my community began to see the BR differently, as more of a special place') 


\section{RESPONSE \\ EFFICIENCY AND \\ EFFECTIVENESS}

Enhances the efficiency and effectiveness of responding to other issues within the problem domain

\section{ADDRESSING OTHER ISSUES}

Outgrowth(s) from the initial arrangement to address additional issues within the problem domain

OTHER
Other second order outcomes that do not fit within existing sub-categories
This also may or may not be evident in some of the documents you collect.

References to the way (process by which) other issues are dealt with; more effective and/or efficient approaches or experiences in responding to issues other than those for which the

\section{ACM is intended}

For example, a hypothetical comment by a respondent may be:

'We found that dealing with community issues outside the BR but where the issues may affect us is easier since we have a

management structure and specific individuals who deal with this' The actual responses to other issues - what was actually done?

For example, using the above hypothetical response, creating a role for a person to be a community liaison would be coded in this sub-category. It is the actual response to the issues outside of the $\mathrm{BR}$, and their response in this case resulted in response efficiency and effectiveness (but that would not always be the case)

\section{Component 4: Effects}

Table A5.4 Adapted from Plummer and Armitage (2007) and others where noted.

\begin{tabular}{ll}
\hline Variable & Description \\
$3^{\text {rd }}$ tier variable: ECOLOGICAL \\
$4^{\text {th }}$ tier variable & $\begin{array}{l}\text { Description } \\
\text { COMPONENT }\end{array}$ \\
& $\begin{array}{l}\text { bomponents that make up the ecological/ } \\
\text { biophysical system. }\end{array}$ \\
& $\begin{array}{l}\text { From Cumming et al (2005): "System components } \\
\text { can be thought of as the }\end{array}$
\end{tabular}

Key words and phrases

Key words and phrases

Species

Stocks (population [number] of a species)

Landscape change

can be thought of as the

Vegetation patterns

Hydrology (References to water movement, quality, etc. within the system both above and below ground) 
RELATIONSHIPS Relationships and interactions among components of the ecological system.

From Cumming et al. (2005): "Relationships describe the ways in which system components interact or fit together. In a system diagram, they would be the causal or logical arrows that link boxes ('edges' in graph theory). Relationships of interest in most study systems include such things as nutrient cycles, food webs and trophic interactions (relating different organisms to one another and to the abiotic environment, ...), economic and ecological competition".

\section{DIVERSITY}

Biological diversity of the system and response diversity (different responses to environmental change among species within the system).
Ecological components

Climate components (air quality, temperature, sunlight, etc.)

Entities (Broader term than species that includes abiotic elements of the ecosystem)

Habitat

Natural resources

Goods and materials (marketable and non-marketable)

Individuals (an individual within a population [e.g., a single fish])

Population (all the individuals of a particular species within a defined area)

Ecological processes (Interactions among elements/components within the ecosystem that occur continuously over time such as photosynthesis, nutrient cycling, decomposition)

Species interactions (interactions among two or more species, including predator-prey interactions)

Productivity and biomass (the production/accumulation of biotic material [e.g., grasses, trees, crops)

Food web disruptions

Ecosystem functions (The collective ways in which the natural elements of the ecosystem interact - i.e., what the elements of the ecosystem actually do when they interact)

Process or interaction variables that link components

Dependency (A requirement of specific conditions for the survival/existence/fitness of an element of the ecosystem on another. For example, when one species is dependent on another for survival) Competition (Interaction between at least two organisms or species where the fitness of one is reduced by another)

Species richness and diversity (Number of different species or degree of variation within a collection of individuals)

Response diversity ("Range of reactions to environmental change among species contributing to the same ecosystem function" Elmqvist et al. (2003)) 
From Cumming et al. (2005): "The sources of innovation are those subsets of the system that generate change or novelty. They

may include or be closely related to such things as diversity ..., migration"

MEMORY
Biodiversity (degree of variation of life forms within a given boundary [e.g., a watershed])

Adjustment (Process of adapting to changing conditions)

Novelty (unfamiliar/new physical, chemical or biological changes to the ecosystem or components of it)

Ecosystem protection (e.g., creation/existence of parks and protected areas, zoning for protection)

Landscape patchiness (homogenous areas that differ from the surrounding landscape), landscape mosaics (describes the pattern of patches of a landscape)

Corridors (contiguous and homogeneous areas that allow for movement of wildlife), networks for wildlife (interconnected corridors)

Maintain identity in space and time (from an ecosystem perspective this would be akin to maintaining a relatively similar system configuration [e.g., same species, same functions] over time and within space

Banks (e.g. seed banks)

Legacies remaining after disturbances (from an ecological perspective these are the reservoirs from which a recovery from disturbance is possible such as important species for seed dispersal, organic material for nutrients for growth, etc.)

Recruitment (the supply of new, young individuals to a population of a particular species [e.g., the growth and development of juvenile fish to increase the population of salmon in a river system])

Laws (e.g., zoning or parks creation as mentioned above) something that explicitly conserves and/or preserves (i.e. says this is what the law is, and this is what it does). $3^{\text {rd }}$ tier variable: LIVELIHOOD ASSETS

\section{$4^{\text {th }}$ tier variable Description}

HUMAN Human capital
Key words and phrases

skills, knowledge, health, etc. 


\begin{tabular}{|c|c|c|}
\hline SOCIAL & Social capital & $\begin{array}{l}\text { networks, groups, rules, norms, sanctions; relationships of trust, reciprocity, } \\
\text { exchange }\end{array}$ \\
\hline NATURAL & Natural capital & stocks (fish) and key ecological services (nutrient cycling) \\
\hline PHYSICAL & Physical capital & infrastructure and producer goods \\
\hline FINANCIAL & Financial capital & $\begin{array}{l}\text { financial resources - cash, bank deposits, livestock, jewels and regular inflows } \\
\text { of money }\end{array}$ \\
\hline
\end{tabular}

\section{References}

Berkes, F. 2004. Rethinking community-based conservation. Conservation Biology 18(3):621- 630.

Chambers, R., Conway, G.R., 1991. Sustainable rural livelihoods: practical concepts for the 21st century. IDS Discussion Paper. 296 pp.

Crona, B. I., and J. N. Parker. 2012. Learning in support of governance: theories, methods, and a framework to assess how bridging organizations contribute to adaptive resource governance. Ecology and Society 17(1): 32.

Department for international development (DFID), 1999. Sustainable Livelihoods Guidance Sheets. DFID, London.

Innes, J.E., Booher, D.E., 1999. Consensus building and complex adaptive systems: a framework for evaluating collaborative planning. Journal of the American Planning Association 65 (4), 412-423.

Olsson, P., C. Folke, and T. Hahn. 2004. Social- ecological transformation for ecosystem management: the development of adaptive co-management of a wetland landscape in southern Sweden. Ecology and Society 9(4): 2. [online] URL:

http://www.ecologyandsociety.org/vol9/iss4/art2.

Plummer, R. 2009. The adaptive co-management process: an initial synthesis of representative models and influential variables. Ecology and Society 14(2): 24. [online] URL: http://www.ecologyandsociety.org/vol14/iss2/art24/ 
Plummer, R. and D. Armitage. 2007. A resilience -based framework for evaluating adaptive co-management: Linking ecology, economics and society in a complex world. Ecological Economics. 61:62-74. 